Gut, 1961, 2, 32

\title{
The histamine test meal in the rat
}

\author{
L. S. VALBERG ${ }^{1}$ AND L. J. WITTS \\ From the Nuffield Department of Clinical Medicine, Radcliffe Infirmary, Oxford
}

SYNOPSIS A histamine test meal is described for the estimation of the secretion of gastric acid and pepsin in the unanaesthetized intact rat.

The stomach of the rat secreted pepsin and a small amount of acid in response to the test meal of hypertonic sucrose. Stimulation with histamine produced a pronounced rise in acid secretion but the output of pepsin remained unchanged. The increase in acid secretion was correlated in the individual rat with a rise in the volume of gastric secretion. Histamine phosphate in a dose of 50 $\mathrm{mg}$. $/ \mathrm{kg}$. body weight produced maximal stimulation of gastric acid secretion and was free from toxic effects. Choline chloride, in a dose of $126.5 \mathrm{mg} . / \mathrm{kg}$. body weight, had no effect on the volume of gastric secretion and it was ineffective as a stimulant of either acid or pepsin secretion.

There are conflicting reports in the literature on the effectiveness of histamine and choline as gastric stimulants in the rat. Roe and Dyer (1939), Friedman (1943), and Komarov, Shay, Rayport, and Fels (1944), using rats in which the pylorus had been ligated, reported that histamine had little if any stimulating effect on the volume and acidity of gastric secretion. Using a similar but improved technique, Kyle and Welbourn (1956) reported that histamine given in doses of $3.6 \mathrm{mg}$. $/ \mathrm{kg}$. body weight per hour produced a $50 \%$ increase in both the volume and acidity of gastric secretion in the rat. Lane, Ivy, and Ivy (1957) found that histamine had a pronounced effect on the acid secretion of the rat with a gastric fistula; similar results were obtained by Ghosh and Schild (1955).

In 1944, Komarov and his colleagues, using the anaesthetized rat in which the pylorus had been ligated, reported that choline was an effective stimulant of both gastric acid and pepsin secretion. They stated, 'We have been so impressed with the relatively uniform effect of choline chloride upon gastric scretion that we have adopted it as a routine agent for testing secretory function in the rat'. To the best of our knowledge no other studies of the efficacy of choline as a gastric stimulant have been reported.

A substantial improvement in the method of studying gastric acid secretion was made by Thornton and Clifton (1959), who devised a test meal technique suitable for the unanaesthetized intact rat. This method involves instilling a test meal containing

${ }^{2}$ Medical Research Fellow, National Research Council of Canada. sucrose and phenol red into an animal's stomach with a catheter. The gastric contents are aspirated after $\mathbf{4 5}$ minutes, and the levels of acid and phenol red are measured. The concentration of phenol red is used to calculate both the volume of gastric secretion and the amount of acid that passed through the pylorus during the test period. Using this method they found histamine phosphate, in a dose of $12 \mathrm{mg}$. $/ \mathrm{kg}$. body weight, an effective stimulant of gastric acid secretion.

In the present investigation the procedure described by Thornton and Clifton (1959) has been modified in several ways and the method has been expanded to include the estimation of gastric pepsin. The technique has been used to reassess the effects of histamine and choline on the volume and acidity of gastric secretion and to determine the effect of these drugs on gastric motility and the secretion of pepsin. The investigation was carried out in two parts. First, a study was made of the effect of graded amounts of histamine on gastric function in order to determine a dose that would give a maximal stimulus. Secondly, the effect of this dose of histamine was compared with injections of saline and choline chloride.

\section{METHODS}

RATS AND THEIR CARE Female rats of the Wistar strain weighing about $250 \mathrm{~g}$. were used. They were kept in individual cages with wide-mesh floors. The animals were deprived of food for 48 hours before the test and fluid was provided in the form of distilled water which contained $10 \%$ sucrose, $0.25 \% \mathrm{NaCl}$, and $0.25 \% \mathrm{KCl}$. 


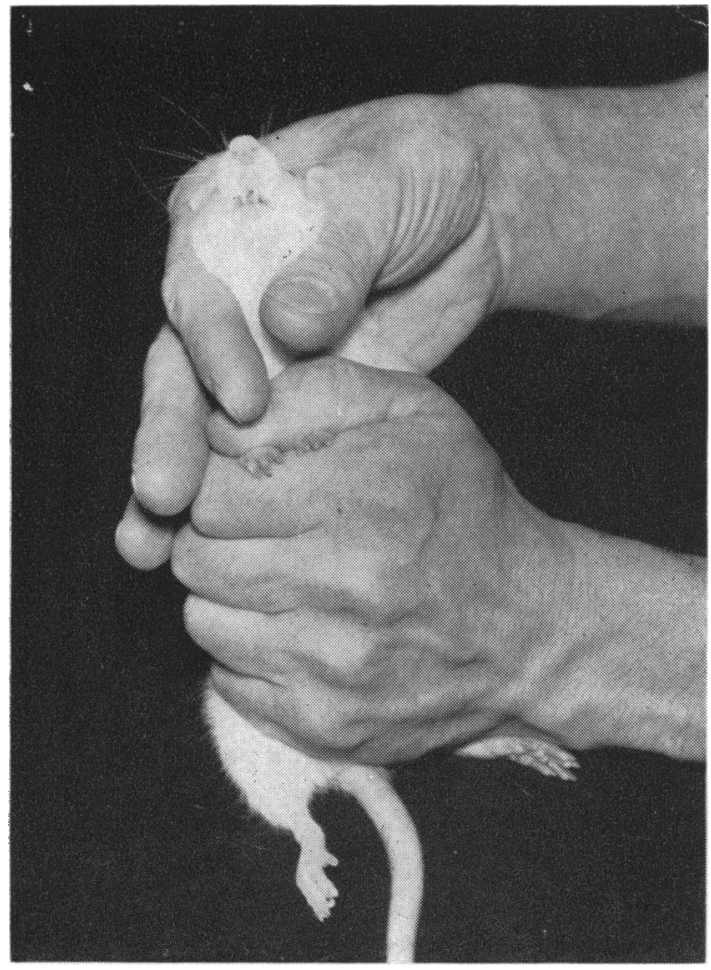

FIG. 1. Position of rat for intubation.

TEST MEAL The test meal used in this study was similar to that described by Thornton and Clifton (1959) except that the final $\mathrm{pH}$ of the solution was adjusted to 5.0 rather than 6.5 , since pepsin is more stable at the lower $p \mathrm{H}$ (Linde, 1950). Only $5 \mathrm{ml}$. of the test meal was administered to each rat as larger volumes tended to exceed the capacity of the stomach. Thornton and Clifton assumed that phenol red was not absorbed from the stomach of the rat and could be quantitatively recovered. In nine rats in which the pylorus had been ligated, we found that on the average $97 \%$ of phenol red could be recovered from the stomach two minutes after instillation and $94 \%$ after 45 minutes. Although some loss appears to occur it is not sufficient to make the use of phenol red impracticable.

INTUBATION OF ANIMALS AND ADMINISTRATION OF TEST MEAL The simple method of intubation described by Thornton and Clifton is only applicable to animals that have been repeatedly intubated. Since this was impracticable in the present study, a method was devised for restraining and intubating the animals. The rat was held by an attendant as shown in Fig. 1. The fore-paws and skin over the abdomen were grasped firmly with the left hand while the animal's head was held between the thumb and index finger of the other hand. A flattened perspex rod, with a groove on the upper edge, was used to hold the animal's mouth open and to press the tongue forward, while a rubber catheter (No. 4 English gauge), lubricated with K-Y jelly, was passed into the pharynx and pushed down the oesophagus. The stomach was washed out with aliquots of saline until a clear return was obtained. Then $5 \mathrm{ml}$. of air was injected into the stomach and this was aspirated to ensure that no fluid had been left behind. The catheter was withdrawn and the animals were permitted to recover for five minutes. The gastric secretory stimulant was given by injection and the rat was then re-intubated with a fine, No. 1 gumelastic catheter and $5 \mathrm{ml}$. of the test meal was injected into the stomach.

The gastric contents were aspirated with a No. 4 rubber catheter 45 minutes later and the stomach was washed out with $5 \mathrm{ml}$. of saline. The specimens were collected in centrifuge tubes and these were centrifuged at $1,000 \mathrm{~g}$ for 15 minutes.

DETERMINATION OF PHENOL RED AND TOTAL ACID CONTENT Wherever the volume of the gastric contents permitted, duplicate estimations of phenol red, total acid, and pepsin were made. Phenol red was measured in the gastric contents and washout by diluting them respectively, 1 to 25 and 1 to 3, with $0.5 \mathrm{M}$-sodium phosphate buffer at $p \mathrm{H} 10$. The optical density of the solutions was measured in a spectrophotometer at $560 \mathrm{~m} \mu$.

The gastric contents and washout were titrated with $0.01 \mathrm{~N}-\mathrm{NaOH}$ in a combined calomel reference electrode and microtitration vessel to the initial $p \mathrm{H}$ of the test meal.

DETERMINATION OF PEPSIN A micromethod for the estimation of pepsin was developed from the method of Anson (1938). Albumin was chosen as a substrate in place of haemoglobin, because the blank solutions of the latter produced unduly high extinction coefficients. Crystalline bovine plasma albumin ( $3.5 \mathrm{~g}$.) was dissolved in $95 \mathrm{ml}$. of distilled water and the $\mathrm{pH}$ lowered to 1.4 with $\mathrm{HCl}$. The volume was made up to $100 \mathrm{ml}$., the $p \mathrm{H}$ checked again, and the solution stored in the refrigerator. Trichloracetic acid was prepared by collecting the fractions distilling between $196^{\circ}$ and $199^{\circ} \mathrm{C}$. from Analar trichloracetic acid.

For the assay the gastric contents were diluted 1 in 6 with distilled water. The gastric washout was tested without dilution. Of each solution to be tested, $0.2 \mathrm{ml}$. was added to three $1.3 \times 5.3 \mathrm{~cm}$. flat-bottomed tubes. One of the tubes served as the blank and $1.0 \mathrm{ml}$. of trichloracetic acid was added to it. The tubes were placed along with the albumin substrate in a water bath at $37^{\circ} \mathrm{C}$. Albumin solution $(0.5 \mathrm{ml}$.) was added to each tube and the contents mixed by partial inversion. After 10 minutes' incubation $1.0 \mathrm{ml}$. of $0.5 \mathrm{M}$-trichloracetic acid was added, the tubes were gently tapped, allowed to stand for 10 minutes, and then centrifuged at $1,000 \mathrm{~g}$ for 15 minutes. One millilitre of clear supernatant was removed from each tube and added to $1.0 \mathrm{ml}$. of distilled water in a $1 \times 7.5 \mathrm{~cm}$. test tube. The optical density of the solutions was measured at $276 \mathrm{~m} \mu$ in silica micro-cells with a light path of $4 \mathrm{~cm}$. The optical density was transformed into units of pepsin per millilitre by reference either to a standard graph or a standard tyrosine solution.

One unit of pepsin was defined as that amount of 
pepsin, which when incubated with albumin substrate under the conditions specified, liberated $6.0 \times 10^{-4} \mathrm{mEq}$. of tyrosine-like substances in $1 \mathrm{ml}$. of supernatant. By employing this unit the results were of similar magnitude to those obtained by the Folin method (Aitken, Spray, and Walters, 1954). In evaluating the procedure experimental evidence was obtained to show that (1) the albumin concentration is adequate for maximum enzyme activity; (2) $0.5 \mathrm{M}$-trichloracetic acid is an efficient protein precipitant in the proportions used; (3) the $p H$ optimum is 1.4 to 1.5 ; (4) the absorption maximum of the supernatant from a digestion mixture is $276 \mathrm{~m} \mu$; (5) a linear relationship exists between incubation time and optional density for a period of 60 minutes; (6) for practical purposes a linear relationship exists between enzyme concentration and optical density; (7) the coefficient of variation of the method is $2 \%$.

ACCURACY OF THE METHOD Complete aspiration of the living rat's stomach is not easy, and any fluid not aspirated after the preliminary lavage will be added to the test meal. The measurements of $p H$ and pepsin in the test meal are therefore probably more reliable than those of volume of secretion and total secretion of acid.

\section{THE OPTIMAL DOSE OF HISTAMINE IN THE RAT}

Gastric analyses were performed on 24 rats of the Wistar strain which were divided into eight equal groups and given respectively, by subcutaneous injection, $0,4,12,25,50,75,150$, and $250 \mathrm{mg}$. $/ \mathrm{kg}$. body weight of histamine phosphate. The animals were not protected by an antihistaminic drug. One death occured in the group that received the largest dose of histamine, otherwise no toxic effects were observed. Examination of the gastric mucosa after the test meals revealed no abnormality. These results in the intact rat are in contrast to studies of Kyle and Welbourn (1956) who found that the incidence of ulceration of the gastric mucosa of rats in which the pylorus had been ligated was twice as great in animals that had received histamine as in comparable controls.

The stomach of the rat secreted pepsin and a small amount of acid in response to the test meal of hypertonic sucrose alone.

Histamine phosphate in doses up to $25 \mathrm{mg} . / \mathrm{kg}$. body weight produced a progressive rise in acid secretion; however, a further increase in the dosage was not followed by appreciable change in the output of acid (Fig. 2). Pepsin secretion, volume of gastric secretion, and gastric emptying were unaffected by histamine.

Doses of histamine ranging from $0.01 \mathrm{mg}$. to 15 $\mathrm{mg} . / \mathrm{kg}$. body weight have been used in the past to stimulate gastric acid secretion in the rat (Roe and Dyer, 1939; Friedman, 1943; Kyle and Welbourn, 1956; Komarov, et al., 1944; Lane, Ivy, and Ivy,

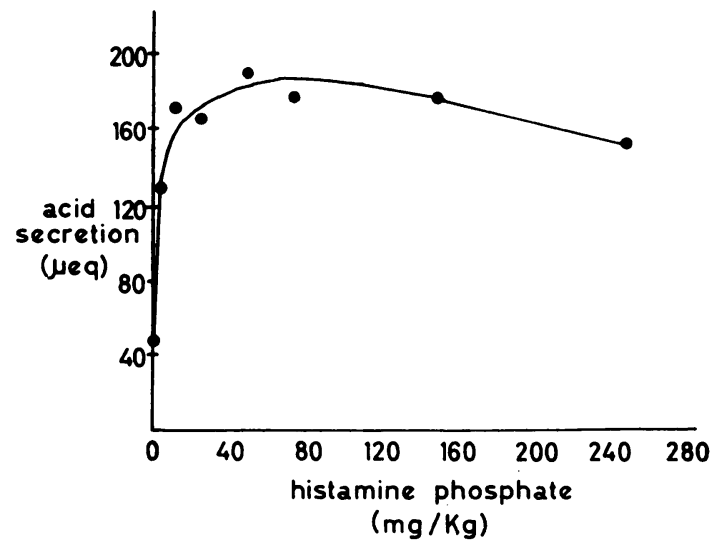

FIG. 2. Effect of graded doses of histamine on gastric acid secretion.

1957; Ghosh and Schild, 1955; Thornton and Clifton, 1959). When compared with the effect of histamine in the present study these levels are suboptimal. To assess adequately the capacity of the stomach to produce acid it would appear desirable to give a stimulus that induces a secretion of acid which represents the maximal parietal-cell output for that particular animal. The stimulus should be large enough to take account of individual susceptibility to histamine and it should be free from toxic effects. On the basis of our findings a dose of $\mathbf{5 0}$ $\mathrm{mg} . / \mathrm{kg}$. body weight of histamine phosphate would appear to fulfil these criteria. The absence of toxic effects with this rather high dose is not surprising in the light of the work by Rose and Browne (1938) who clearly showed that the rat is tolerant of large amounts of histamine.

The dose of histamine required for maximum stimulation of acid secretion in the rat is about 1,000 times greater than that required in man (Kay, 1953) and about 100 to 1,000 times greater than the doses used in the dog (Bowie and Vineberg, 1935; Hanson, Grossman, and Ivy, 1948). The disagreement of previous workers on the efficacy of histamine as a stimulant of gastric secretion in the rat is undoubtedly related to the failure to give adequate amounts and to the variable and unphysiological techniques that have been employed to test gastric function.

\section{THE EFFECT OF CHOLINE AND HISTAMINE ON GASTRIC FUNCTION IN THE RAT}

Sixteen rats were divided into two groups and gastric analyses were performed after they had been given, respectively, saline and choline chloride, $126.5 \mathrm{mg}$./ kg. body weight, by subcutaneous injection. The 

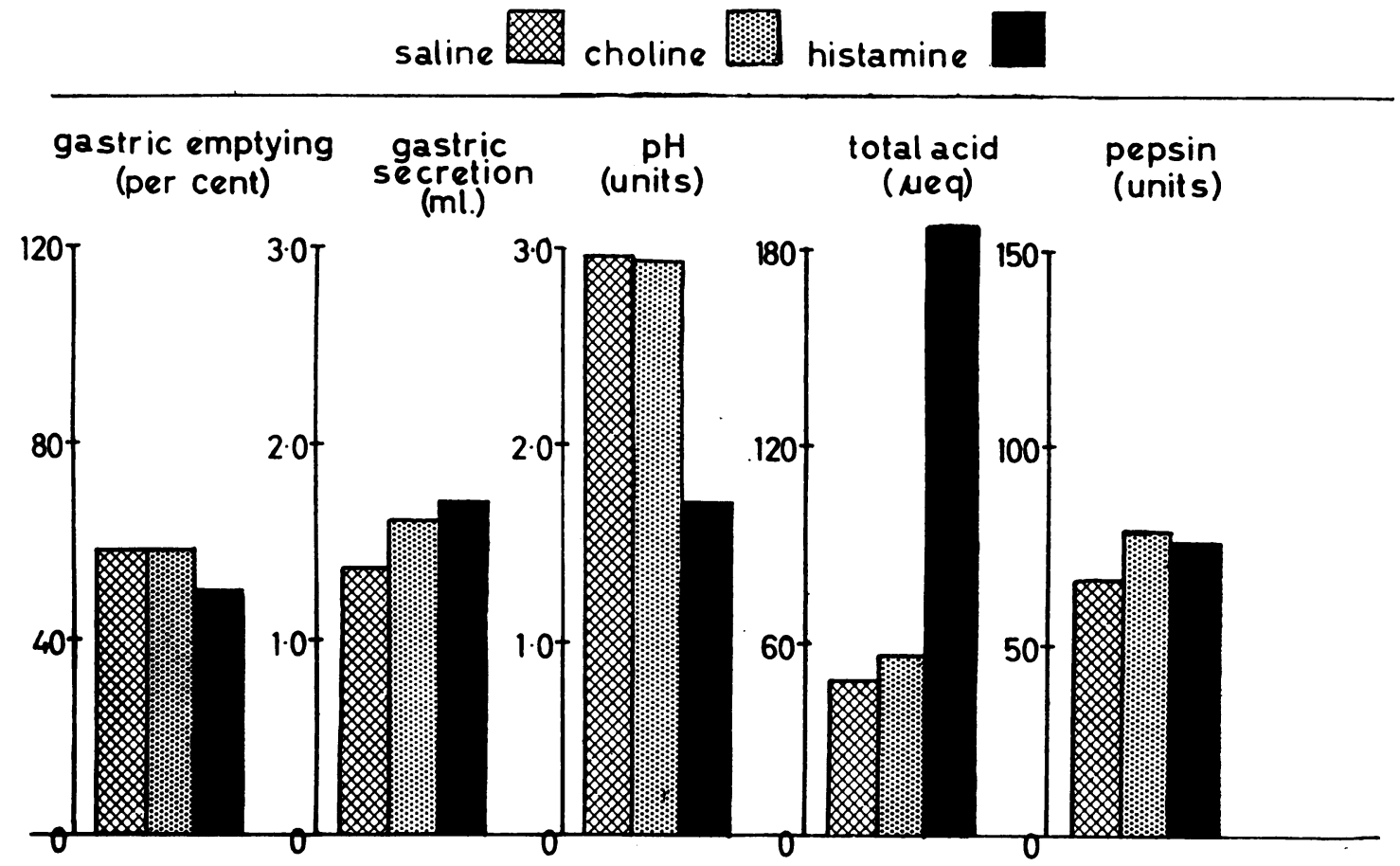

FIG. 3. Effect of choline and histamine on gastric emptying (percentage of meal and secretion passed through pylorus). gastric secretion, $p \mathrm{H}$, and total output of acid and pepsin.

dose of choline chloride was equivalent, on an equimolar basis, to $278 \mathrm{mg} . / \mathrm{kg}$. body weight of histamine phosphate and it was within the range of dosage recommended by Komarov et al. (1944). Gastric analyses were also performed on 31 rats which received injections of histamine phosphate, $50 \mathrm{mg}$. $/ \mathrm{kg}$. body weight.

The results are shown in Fig. 3. Choline chloride in a dose of $126.5 \mathrm{mg} . / \mathrm{kg}$. body weight was found to have no greater effect on gastric emptying, gastric secretion, acid production, or pepsin output than an equivalent volume of saline. These findings disagree with those of Komarov and his colleagues (1944) who found, in the anaesthetized rat with a ligated pylorus and a gastric fistula, that injections of choline chloride increased the volume of gastric secretion from $0.08 \mathrm{ml}$. to $0.33 \mathrm{ml}$./hour and increased the output of acid from $8.8 \mu \mathrm{Eq}$. to 37 $\mu \mathrm{Eq}$./hour. These values are unusually low and even those of the choline-treated group are lower than the results obtained in the present study with injections of saline. In the light of subsequent improvements (Shay, Sun, and Gruenstein, 1954) that were made in the preparation of the 'pylorus-ligated rat' for the study of gastric function the technique used by Komarov et al. was crude and rather inadequate.

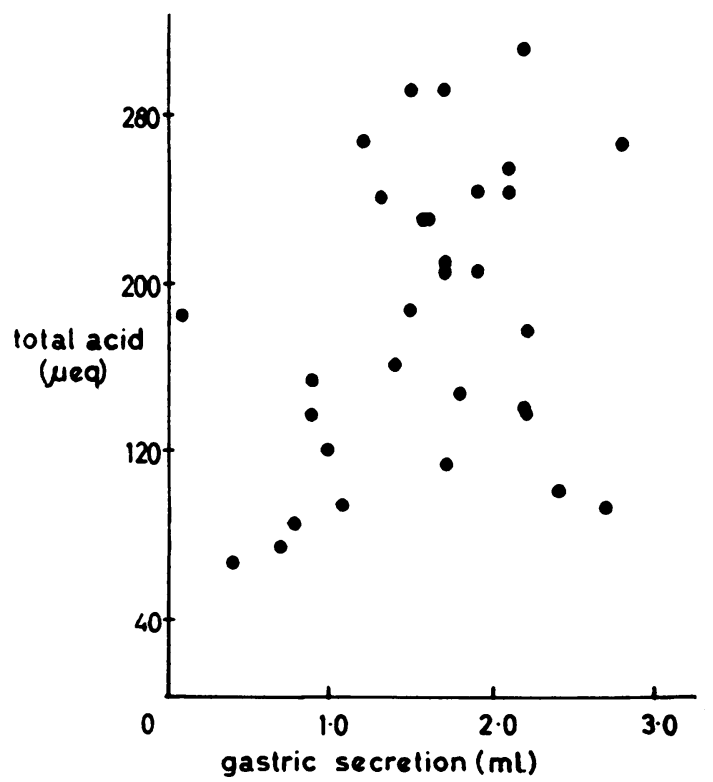

FIG. 4. Relationship of total acid secretion to the volume of gastric secretion during the 45-minute test meal. 


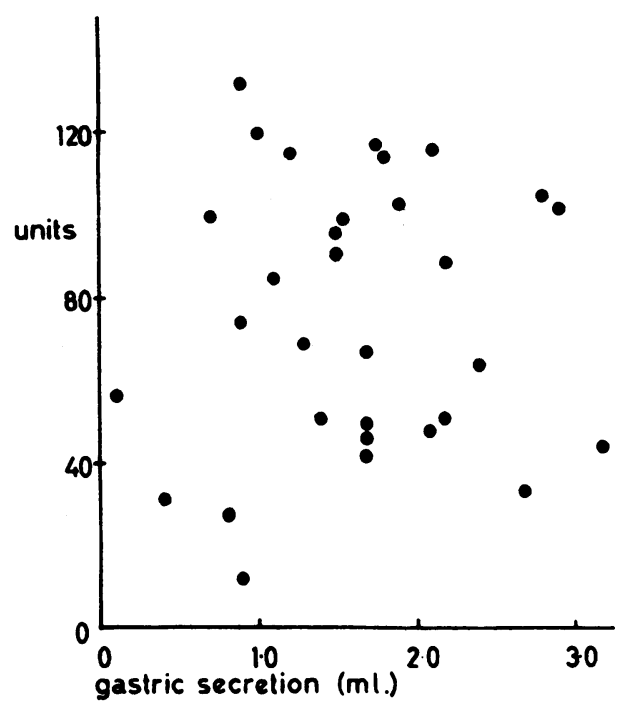

FIG. 5. Relationship of total pepsin secretion to the volume of gastric secretion during the 45-minute test meal.

It will be seen from Fig. 3 that although histamine phosphate had a pronounced effect on the output of acid its effect on pepsin secretion and gastric emptying was no greater than that of saline. The volume of gastric secretion was slightly greater in the histamine-treated group but the difference was not significant. However, when the individual results were plotted, there was a definite correlation between the amount of acid produced and the volume of gastric secretion which was significant at $\mathbf{P}<0.01$ (Fig. 4).

No interrelationship was found between gastric emptying and the other indices. Of the other parameters, no correlation was observed between acid and pepsin secretion (Fig. 5). The finding of sub- stantial amounts of pepsin in the gastric secretion of the saline-treated group and similar quantities in the histamine- and choline-treated groups suggests that pepsin is continuously secreted by the gastric mucosa. The failure of histamine to stimulate the secretion of pepsin in the rat is in accord with the findings in the dog and the cat (Linde, 1950). These results are in contrast to those found in man where histamine has been shown to be an effective stimulant of gastric pepsin secretion (Hirschowitz, London, and Pollard, 1957).

We are indebted to Mr. J. R. P. O'Brien and Mr. G. E. Newman for helpful advice and we are grateful to $\mathrm{Mr}$. J. Halfacree, Miss Roberta Crawley, and Miss Cecily Bubb for technical assistance. This work was supported by a grant to Professor L. J. Witts from the Medical Research Council.

\section{REFERENCES}

Aitken, M. A., Spray, G. H., and Walters, G. (1954). Clin. Sci., 13, 119-126.

Anson, M. L. (1938). J. gen. Physiol., 22, 79-89.

Bowie, D. J., and Vineberg, A. M. (1935). Quart. J. exp. Physiol., 25, 247-257.

Friedman, M. H. F. (1943). Proc. Soc. exp. Biol. (N. Y.), 54, $42-44$. Ghosh, M. N., and Schild, H. O. (1955). J. Physiol. (Lond.), 128, 35P-36P.

Hanson, M. E., Grossman, M. I., and Ivy, A. C. (1948). Amer. J. Physiol., 153, 242-258.

Hirschowitz, B. I., London, J. L., and Pollard, H. M. (1957). Gastroenterology, 32, 85-87.

Kay, A. W. (1953). Brit. med. J., 2, 77.

Komarov, S. A., Shay, H., Rayport, M., and Fels, S. S. (1944). Gastroenterology, 3, 406-413.

Kyle, J., and Welbourn, R. B. (1956). Ibid, 30, 593-597.

Lane, A., Ivy, A. C., and Ivy, E. K. (1957). Amer. J. Physiol., 190, 221-228.

Linde, S. (1950). Acta physiol. scand., Suppl. 74.

Roe, J. H., and Dyer, H. M. (1939). Proc. Soc. exp. Biol. (N.Y.), 41, 603-606.

Rose, B., and Browne, J. S. L. (1938). Amer. J. Physiol., 124, 412-420.

Shay, H., Sun, D. C. H., and Gruenstein, M. (1954). Gastroenterology, 26, 906-913.

Thornton, G. H. M., and Clifton, J. A. (1959). Amer. J. Physiol., 197, 263-268. 